\title{
Palliative and prognostic approach in cancer patients identified in the multicentre NECesidades PALiativas 2 study in Argentina
}

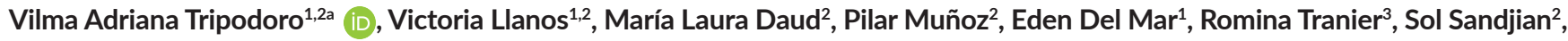 \\ Silvina De Lellis ${ }^{2}$, Juan Manuel Días ${ }^{2}$, Alvaro Saurí3 ${ }^{3}$ Gustavo Gabriel De Simone ${ }^{2,4}$ and Xavier Gómez-Batiste ${ }^{5}$ \\ ${ }^{1}$ Instituto de Investigaciones Médicas Alfredo Lanari, Universidad de Buenos Aires, Av Combatientes de Malvinas 3150, C1427 ARN, \\ Buenos Aires, Argentina \\ ${ }^{2}$ Instituto Pallium Latinoamérica, Bonpland 2257 (1425), Ciudad de Buenos Aires, Argentina \\ ${ }^{3}$ Instituto de Oncología Ángel Roffo, Universidad de Buenos Aires, Av San Martín 5481 (1417), Ciudad de Buenos Aires, Argentina \\ ${ }^{4}$ Hospital de Gastroenterología Dr. Carlos Bonorino Udaondo, Av Caseros 2061 (1264), Ciudad de Buenos Aires, Argentina \\ ${ }^{5}$ Cátedra de Cuidados Paliativos, Universitat de Vic-Universitat Central de Catalunya, C Miquel Martí i Pol 1, 08500 Vic, Catalonia, Spain \\ ahttps://orcid.org/0000-0003-2328-6032
}

\section{Abstract}

Background: Early identification of palliative needs has proven benefits in quality of life, survival and decision-making. The NECesidades PALiativas (NECPAL) Centro Coordinador Organización Mundial de la Salud - Instituto Catalán de Oncología (CCOMS-ICOC) tool combines the physician's insight with objective disease progression parameters and advanced chronic conditions. Some parameters have been independently associated with mortality risk in different populations. According to the concept of the 'prognostic approach' as a companion of the 'palliative approach', predictive models that identify individuals at high mortality risk are needed.

Objective: We aimed to identify prognostic factors of mortality in cancer in our cultural context.

Method: We assessed cancer patients with palliative needs until death using this validated predictive tool at three hospitals in Buenos Aires City. This multifactorial, quantitative and qualitative non-dichotomous assessment process combines subjective perception (the surprise question: Would you be surprised if this patient dies in the next year?) with other parameters, including the request (and need) for palliative care (PC), the assessment of disease severity, geriatric syndromes, psychosocial factors and comorbidities, as well as the use of healthcare resources.

Results: 2,104 cancer patients were identified, 681 were NECPAL+ (32.3\%). During a 2-year follow-up period, 422 NECPAL+ patients died (61.9\%). The mean overall survival was 8 months. A multivariate model was constructed with significant indicators in univariate analysis. The best predictors of mortality were: nutritional decline $(p<0.000)$, functional decline $(p<0.000)$, palliative performance scale (PPS) $\leq 50(p<0.000)$, persistent symptoms $(p<0.002)$, functional dependence $(p<0.000)$, poor treatment response $(p<0.000)$, primary cancer diagnosis $(p=0.024)$ and condition (in/outpatients) $(p<0.000)$. Only three variables remained as survival predictors: low response to treatment $(p<0.001)$, PPS $\leq 50$ $(p<0.000)$ and condition (in/outpatients) $(p<0.000)$.

Correspondence to: Vilma Adriana Tripodoro Email: Vilma.tripodoro@gmail.com

ecancer 2021, 15:1316

https://doi.org/10.3332/ecancer.2021.1316

Published: $10 / 11 / 2021$

Received: 05/07/2021

Publication costs for this article were supported by ecancer (UK Charity number 1176307).

Copyright: (c) the authors; licensee ecancermedicalscience. This is an Open Access article distributed under the terms of the Creative Commons Attribution License (http:// creativecommons.org/licenses/by/4.0), which permits unrestricted use, distribution, and reproduction in any medium, provided the original work is properly cited. 
Conclusion: This prospective model aimed to improve cancer survival prediction and timely PC referral in Argentinian hospitals.

Keywords: advanced cancer, palliative care, chronic disease, prognosis, mortality

\section{Introduction}

Early identification of palliative care (PC) needs has proven benefits in quality of life, survival and decision-making [1]. However, the current PC model of as-needed referral and siloed departments can lead to heterogeneous access and fragmented care [2]. Furthermore, while integrated PC delivery gradually increases in the last year of life, disease-modifying and potentially curative care and unplanned care are not decreasing. Instead, it is rapidly increasing, particularly in the last 3 months of life [3]. Growing evidence shows that the NECesidades PALiativas (NECPAL) Centro Coordinador Organización Mundial de la Salud - Instituto Catalán de Oncología (CCOMS-ICOC) tool is validated with widespread use to identify patients likely in PC needs [4-8]. The combination of the surprise question (SQ) (Would you be surprised if this patient dies in the next year?) and some individual parameters may have potential prognostic utility for estimating mortality in patients with advanced chronic diseases (ACD), including cancer and non-cancer patients $[9,10]$. Predictive models that identify individuals at high mortality risk are needed. Previous studies from our cultural context suggested that cancer patients might not have been detected promptly enough [6-8]. The NECPAL screening tool demonstrated feasibility in hospitals and primary care looking for the prevalence of unmet PC needs.

Recent findings adding a 'prognostic approach' enabling early PC intervention, multidimensional assessment, advanced care planning and case management for patients who may benefit from it [9]. The NECPAL prognostic model, including the SQ and some variables like functional decline, nutritional decline, multimorbidity (Charlson index), use of resources, disease-specific criteria of severity and progression plus age, generally performs well to predict 24-month mortality risk across different clinical conditions and care settings [9, 11].

In Argentina, only $10 \%$ of patients with PC needs have accessibility to PC services [12, 13]. In addition, the early palliative approach can prevent or ameliorate suffering and must be an informed option and available for all $[2,6,14]$. Therefore, we hypothesised that the timely identification supported by a predictive mortality risk model would be necessary for PC National Programme Design in Argentina [3, 15].

According to the concept of the 'prognostic approach' as an additional companion of the necessary 'palliative approach', we aimed to identify risk factors of mortality in cancer patients with PC needs in our cultural context [9]. Therefore, during a larger research project, 'NECPAL 2 Study', we identified and assessed cancer patients with PC needs until death at three hospitals in Buenos Aires City (Lanari and Roffo University of Buenos Aires Institutes and Udaondo Gastroenterology Hospital from the Government of Buenos Aires City). Additionally, 2 years after their identification, the survival analysis was collated with recent international findings [2, 9].

\section{Materials and method}

As part of a more comprehensive intervention-based prospective exploratory design, all $\geq 18$-year-old in/outcancer patients were identified and assessed in three hospitals as part of the NECPAL 2 Study (between June 2016 and July 2018). Following that, the individuals who met these criteria were evaluated regularly, as needed or at least once every 3months, looking for particular PC needs.

The data were gathered by interviews with the medical staff in charge according to the NECPAL CCOMS-ICOC tool V.3.0 [16]. Each hospital's researchers were trained in NECPAL methodology following implementation procedures during a 1-month short training course [6]. Each patient's interview lasted 10 minutes on average. This instrument offers a non-dichotomous multifactorial, quantitative and qualitative assessment method that incorporates subjective perception and the SQ: Would you be surprised if this patient dies in the next year? Positive answers $\left(\mathrm{SQ}^{+}\right)$meant that the doctor would not be surprised. Other specific indicators and the usage of healthcare resources were summarised in Table 1 [16]. Patients considered NECPAL positive (+) are those SQ+ patients who also fulfil at least one of the other indicators of the tool. 
Table 1. The NECPAL CCOMS-ICO @ tool: general indicators of severity and progression and disease-specific indicators [8, 16].

\begin{tabular}{|c|c|}
\hline \multicolumn{2}{|r|}{ The NECPAL tool indicators } \\
\hline $\begin{array}{l}\text { Choice, request or need } \\
\text { of palliative approach }\end{array}$ & $\begin{array}{l}\text { Has the patient or the main caregiver requested palliative/comfort treatments exclusively or suggests limitation of } \\
\text { therapeutic effort? Do healthcare professionals consider that the patient requires PC or palliative treatment at this moment? }\end{array}$ \\
\hline Functional markers & $\begin{array}{l}\text { Serious established functional dependence (Barthel score }<20 \text { ) } \\
\text { Loss of two or more ADLs even though there is adequate therapeutic intervention or clinical perception of functional decline } \\
\text { (sustained, intense/severe, progressive, irreversible) not related to concurrent conditions }\end{array}$ \\
\hline Nutritional markers & $\begin{array}{l}\text { Serum albumin }<2.5 \mathrm{~g} / \mathrm{dl} \text {, not related to acute episodes of unbalance } \\
\text { Weight loss }>10 \% \text { or clinical perception of nutritional decline (sustained, intense/severe, progressive, irreversible) not related } \\
\text { to concurrent conditions }\end{array}$ \\
\hline Emotional & $\begin{array}{l}\text { Presence of emotional distress with psychological symptoms (sustained, intense/severe, progressive) not related to acute } \\
\text { concurrent conditions }\end{array}$ \\
\hline $\begin{array}{l}\text { Geriatric syndromes in } \\
\text { the last } 6 \text { months }\end{array}$ & Persistent pressure ulcers (stages III-IV), recurrent infections (>1), delirium, persistent dysphagia, falls (>2) \\
\hline Comorbidity & Charlson Index [11] \\
\hline $\begin{array}{l}\text { Additional factors on use } \\
\text { of resources }\end{array}$ & $\begin{array}{l}\text { Two or more urgent (unplanned) hospital (or skilled nursing facilities) admissions due to chronic disease in the last year. Need } \\
\text { of complex/intense continuing care, either at an institution or at home }\end{array}$ \\
\hline Cancer (1 single criterion) & $\begin{array}{l}\text { Confirmed diagnosis of metastatic cancer who present low response or contraindication of specific treatment, progressive } \\
\text { outbreak during treatment or metastatic affectation of vital organs } \\
\text { Significant functional deterioration (PPS } \leq 50 \% \text { ) [17] } \\
\text { Persistent, troublesome symptoms, despite optimal treatment of underlying condition(s) }\end{array}$ \\
\hline $\begin{array}{l}\text { Chronic pulmonary } \\
\text { disease ( } \geq 2 \text { criteria) }\end{array}$ & $\begin{array}{l}\text { Breathlessness at rest or on minimal exertion between exacerbations. Difficult physical or psychological symptoms despite } \\
\text { optimal tolerated therapy. FEV1 }<30 \% \text { or criteria of restricted severe deficit: FVC }<40 \% / D L C O<40 \% \text {. Accomplishment of } \\
\text { oxygen therapy at home criteria. Recurrent hospital admissions (>3 admissions in } 12 \text { months due to exacerbations) }\end{array}$ \\
\hline $\begin{array}{l}\text { Chronic heart disease } \\
\text { ( } \geq 2 \text { criteria) }\end{array}$ & $\begin{array}{l}\text { Heart failure NYHA stage III or IV, severe valve disease or inoperable coronary artery disease. Shortness of breath at rest or } \\
\text { minimal exertion. Difficult physical or psychological symptoms despite optimal tolerated therapy. Ejection fraction severely } \\
\text { affected }(<30 \%) \text { or severe pulmonary hypertension }(>60 \mathrm{~mm} \mathrm{Hg}) \text {. Renal failure (GFR }<30 \mathrm{~L} / \text { minute). Repeated hospital } \\
\text { admissions with symptoms of heart failure/ischaemic heart disease ( }>3 \text { in the last year) }\end{array}$ \\
\hline $\begin{array}{l}\text { Serious chronic liver } \\
\text { disease ( } 1 \text { single criterion) }\end{array}$ & $\begin{array}{l}\text { Advanced cirrhosis: stage Child C, MELD-Na Score }>30 \text { or with one or more of the following medical complications: diuretic- } \\
\text { resistant ascites, hepatorenal syndrome or upper gastrointestinal bleeding due to portal hypertension with failed response to } \\
\text { treatment. Hepatocellular carcinoma: present, in stage } C \text { or } D(B C L C)\end{array}$ \\
\hline $\begin{array}{l}\text { Serious chronic renal } \\
\text { disease ( } 1 \text { single criterion) }\end{array}$ & Serious renal failures (GFR $<15$ ) in patients to whom substitutive treatment or transplant is contraindicated \\
\hline $\begin{array}{l}\text { Chronic neurological } \\
\text { diseases [1]: CVA } \\
\text { (1 single criterion) }\end{array}$ & $\begin{array}{l}\text { During acute and subacute phases ( }<3 \text { months post stroke): persistent vegetative or minimal conscious state }>3 \text { days. During } \\
\text { the chronic phase ( }>3 \text { months post stroke): repeated medical complications (aspiration pneumonia, pyelonephritis, recurrent } \\
\text { febrile episodes, pressure ulcers stages } 3-4 \text { or dementia with severe criteria post stroke) }\end{array}$ \\
\hline $\begin{array}{l}\text { Chronic neurological } \\
\text { diseases [2]: MND, } \\
\text { multiple sclerosis and } \\
\text { Parkinson ( } \geq 2 \text { criteria) }\end{array}$ & $\begin{array}{l}\text { Progressive deterioration in physical and/or cognitive function despite optimal therapy. Complex and difficult symptoms. } \\
\text { Speech problems with increasing difficulty communicating. Progressive dysphagia } \\
\text { Recurrent aspiration pneumonia, breathless or respiratory failure }\end{array}$ \\
\hline $\begin{array}{l}\text { Dementia ( } \geq 2 \text { of the } \\
\text { following criteria) }\end{array}$ & $\begin{array}{l}\text { Severity criteria: GDS/FAST 6c or more. Progression criteria: loss of two or more ADLs in the last } 6 \text { months, despite adequate } \\
\text { therapeutic intervention or difficulty swallowing, or denial to eat, in patients who will not receive enteral or parenteral } \\
\text { nutrition. Use of resources criteria: multiple admissions (>3 in } 12 \text { months, due to concurrent processes - aspiration } \\
\text { pneumonia, pyelonephritis, sepsis, etc. - that cause functional and/or cognitive decline) }\end{array}$ \\
\hline
\end{tabular}

ADL, Activities of daily living; BCLC, Barcelona clinic liver cancer; CVA, Cerebrovascular accident; DLCO, Diffusing capacity of the lung for carbon monoxide; FEV1, Forced expiratory volume in $1 \mathrm{~s}$; FVC, Forced vital capacity; GFR, Glomerular filtration rate; NYHA, New York Heart Association; MND, Motor neuron disease; GDS/FAST, Global deterioration scale/functional assessment; MELD-Na, Model for end-stage liver disease 
Cancer patients, identified only by their physicians in charge, were stratified into four levels according to NECPAL methodology (Figure1) [6]. Level 0 diagnosed cancer; Level 1 cancer with ACD; Level 2 cancer with SQ+; Level 3 cancer with SQ+ and at least one indicator listed in Table 1 (NECPAL+). All NECPAL+ patients were followed for 2 years after first identification. A descriptive analysis was conducted on the demographic and clinical indicators of these NECPAL+ patients. According to distribution, continuous variables were expressed as mean values \pm standard deviation and median and range. The flowchart shows the recruitment process according to the institutions involved (Figure 2). It was sorted by levels, SQ+/NECPAL+, in/out and dead patients.

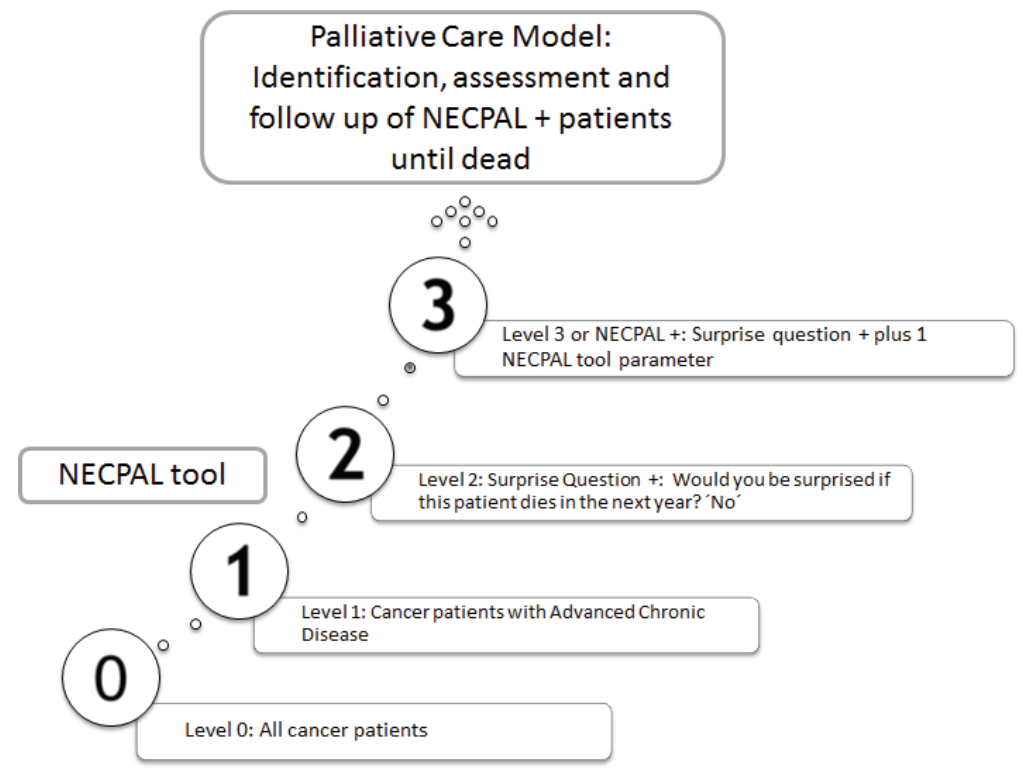

Figure 1. Levels of stratifications according to NECPAL methodology and the PCM. Adapted from Tripodoro et al [6].

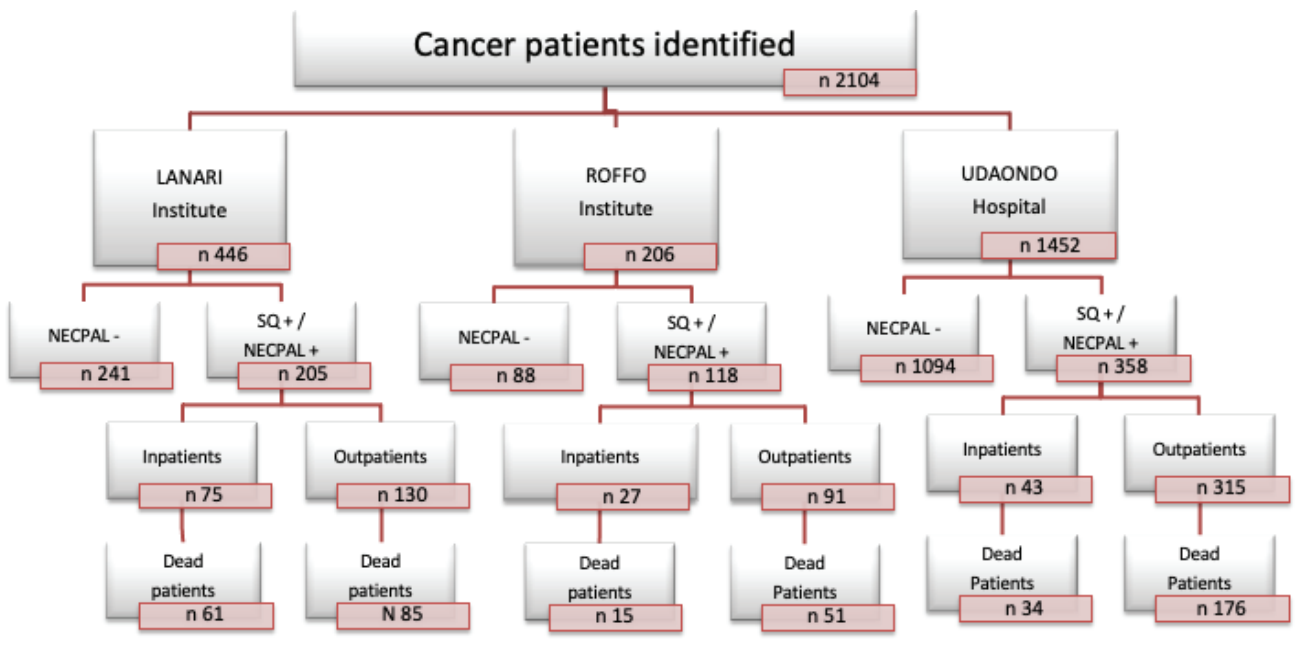

Figure 2. Recruitment process stratification. SQ, Surprise question; NECPAL+, Patients with SQ+ plus at least one of the other parameters of the tool; NECPAL-, Patients who his/her physician would be surprised if the patient would die during next year. 
Survival curves of Kaplan-Meier were performed from the identification date of NECPAL+ patients until death or last control. A cut-off was made 2 years after detecting the first NECPAL+ patient (1 July 2018). All deceased patients were registered, and those referred to other centres or those lost to follow-up were censored. The median follow-up was established for the total sample and for those who had not died. Wald test and hazard ratio were used in Cox proportional analysis to compare groups according to age, gender, primary diagnosis, condition (in/outpatients), metastatic vital organ involvement, nutritional status and functional status (palliative performance scale (PPS) $\leq 50$ ), or other indicators with statistical significance [17]. A multivariate model was constructed with the significant indicators in the univariate analysis with Cox proportional analysis to explore the best predictors of mortality. A value of $p<0.05$ was considered significant. The statistical analysis was carried out by the Statistical Package for Social Science (IBM-SPSS 22 version (SPSS Inc. Chicago, IL)) and Stata V12.

The Ethics Committees approved this study of the institutions involved in the NECPAL 2 Study. It was registered at the National Ministry of Health (RENIS IS001867/IS001871) and funded by the Argentina National Cancer Institute and Pallium Latinoamérica.

\section{Results}

A total of 2,104 cancer patients were found, with 681 being NECPAL+ (32.3\%). During the 2-year follow-up period after identification, 422 NECPAL+ patients died (61.9\%) (Figure 2). The data were collated from three hospitals. Table 2 summarises sociodemographic results, primary cancer diagnoses and NECPAL indicators. A multivariate model was constructed where variables with a higher/lower probability of survival were: nutritional decline ( $p$ 0.000), functional decline ( $p 0.000)$, PPS $\leq 50$ ( $p 0.000)$, persistent symptoms $(p 0.002)$, functional dependence ( $p$ 0.000), low response to treatment ( $p 0.000)$, primary cancer diagnosis ( $p 0.024)$ and condition (in/outpatients) $(p 0.000)$. The only three variables that remained as predictors were: low response to treatment ( $p 0.001)$, PPS $\leq 50(p 0.000)$ and condition (in/outpatients) ( $p$ 0.000). Table 3 characterises the multivariate model. The mean overall survival was 8 months. Figure 3 shows global survival curves (Figure 3a) and significant predictors of mortality from 681 NECPAL+ patients (Figure 3b-d).

Table 2. NECPAL+ patient distribution by characteristics and hospital.

\begin{tabular}{|c|c|c|c|c|c|c|c|}
\hline & \multirow[t]{2}{*}{ Total NECPAL $+(n=681)$} & \multicolumn{2}{|c|}{ Lanari Institute $(n=205)$} & \multicolumn{2}{|c|}{ Roffo Institute ( $n=118$ ) } & \multicolumn{2}{|c|}{ Udaondo Hospital $(n=358)$} \\
\hline & & $\begin{array}{c}\text { Inpatient } \\
(n=75)\end{array}$ & $\begin{array}{c}\text { Outpatient } \\
(n=130)\end{array}$ & $\begin{array}{c}\text { Inpatient } \\
(n=27)\end{array}$ & $\begin{array}{l}\text { Outpatient } \\
(n=91)\end{array}$ & $\begin{array}{c}\text { Inpatient } \\
(n=43)\end{array}$ & $\begin{array}{l}\text { Outpatient } \\
(n=315)\end{array}$ \\
\hline Female & $339(50 \%)$ & $35(47 \%)$ & $72(56 \%)$ & 9 (33\%) & $53(59 \%)$ & $19(44 \%)$ & $150(48 \%)$ \\
\hline Age (mean) & $65(23-99)$ & $76(50-93)$ & $76(38-99)$ & $56(27-77)$ & $63(33-81)$ & $60(32-99)$ & $59(23-91)$ \\
\hline Nutritional decline & $259(38 \%)$ & $42(56 \%)$ & $37(29 \%)$ & $10(37 \%)$ & $19(21 \%)$ & $23(53 \%)$ & $128(41 \%)$ \\
\hline Functional decline & $266(39 \%)$ & $54(72 \%)$ & $66(51 \%)$ & $18(67 \%)$ & $33(37 \%)$ & $17(40 \%)$ & $76(24 \%)$ \\
\hline Functional dependence & 89 (13\%) & $24(32 \%)$ & $17(13 \%)$ & $8(30 \%)$ & $5(6 \%)$ & $7(16 \%)$ & $27(9 \%)$ \\
\hline Breast cancer & $36(5 \%)$ & $7(9 \%)$ & $24(19 \%)$ & $4(15 \%)$ & $1(1 \%)$ & $0(0 \%)$ & $0(0 \%)$ \\
\hline Lung cancer & $118(17 \%)$ & $8(11 \%)$ & $23(18 \%)$ & $3(11 \%)$ & 83 (92\%) & $0(0 \%)$ & $1(0 \%)$ \\
\hline Gastrointestinal cancer & $413(61 \%)$ & $31(41 \%)$ & 25 (19\%) & $7(26 \%)$ & $1(1 \%)$ & $43(100 \%)$ & 305 (97\%) \\
\hline Genitourinary cancer & $35(5 \%)$ & $8(11 \%)$ & $22(17 \%)$ & $2(7 \%)$ & $3(3 \%)$ & $0(0 \%)$ & $0(0 \%)$ \\
\hline Oncohaematologic & $11(2 \%)$ & $5(7 \%)$ & $6(5 \%)$ & $0(0 \%)$ & $0(0 \%)$ & $0(0 \%)$ & $0(0 \%)$ \\
\hline Gynaecologic cancer & $12(2 \%)$ & $1(1 \%)$ & $7(5 \%)$ & $4(15 \%)$ & $0(0 \%)$ & $0(0 \%)$ & $0(0 \%)$ \\
\hline Other & $40(6 \%)$ & $9(12 \%)$ & $19(15 \%)$ & $7(26 \%)$ & $2(2 \%)$ & $0(0 \%)$ & $3(1 \%)$ \\
\hline Primary Unknown & $16(2 \%)$ & $6(8 \%)$ & $3(2 \%)$ & $0(0 \%)$ & $0(0 \%)$ & $0(0 \%)$ & $6(2 \%)$ \\
\hline
\end{tabular}


Table 3. Multivariate model.

\begin{tabular}{|l|c|c|c|c|c|}
\hline & Exposed & Not exposed & Hazard ratio $(95 \% \mathrm{Cl})$ & $p$ value & $\begin{array}{c}\text { Wald } \\
\text { test }\end{array}$ \\
\hline PPS $\leq 50^{\mathrm{a}}$ & 205 & 474 & $1.699(1.351-2.137)$ & $<0.000$ & 20.582 \\
\hline Inpatient $^{\mathrm{a}}$ & 145 & 534 & $1.682(1.327-2.132)$ & $<0.000$ & 18.496 \\
\hline Low response to treatment $^{\mathrm{b}}$ & 291 & 380 & $1.409(1.143-1.738)$ & $<0.001$ & 10.323 \\
\hline
\end{tabular}

a2 missing cases

b10 missing cases

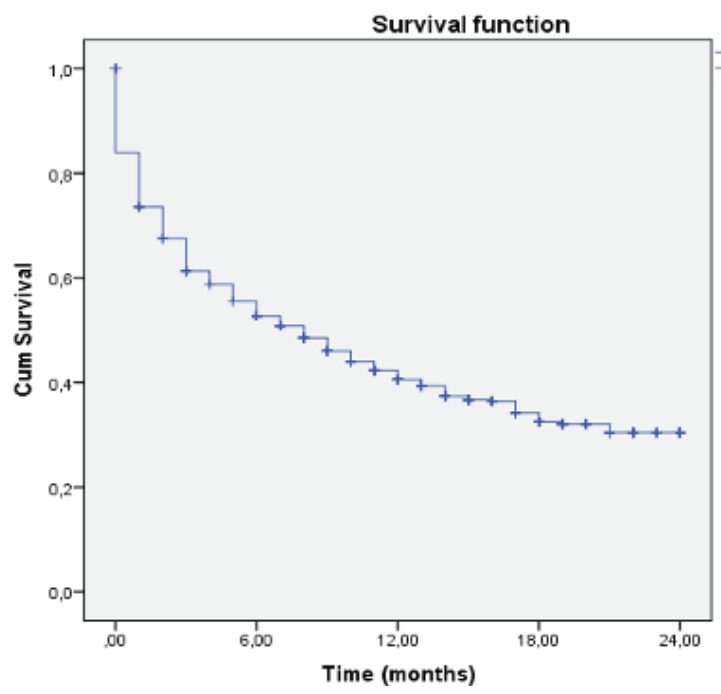

(a)

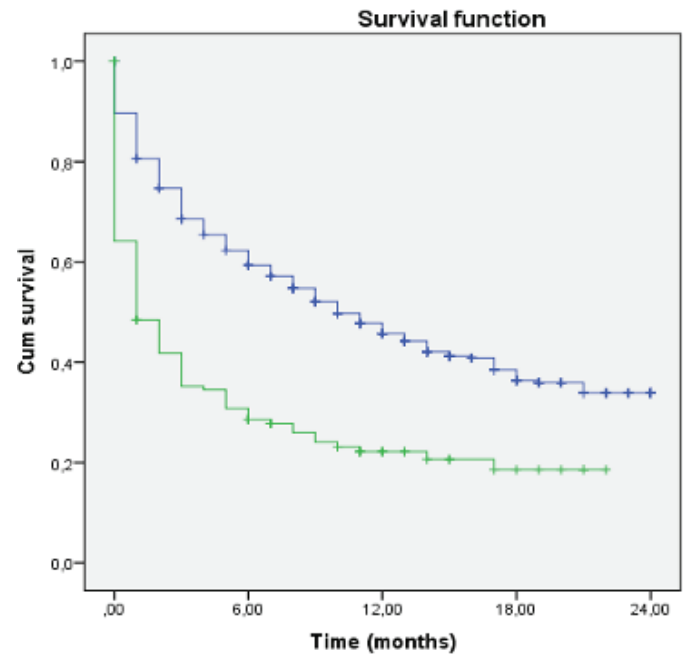

(c)

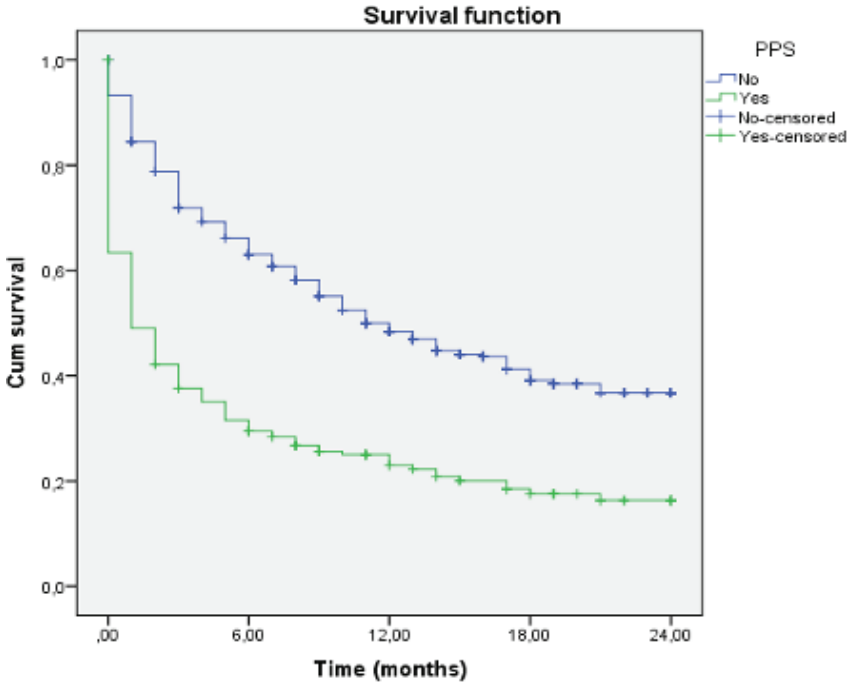

(b)

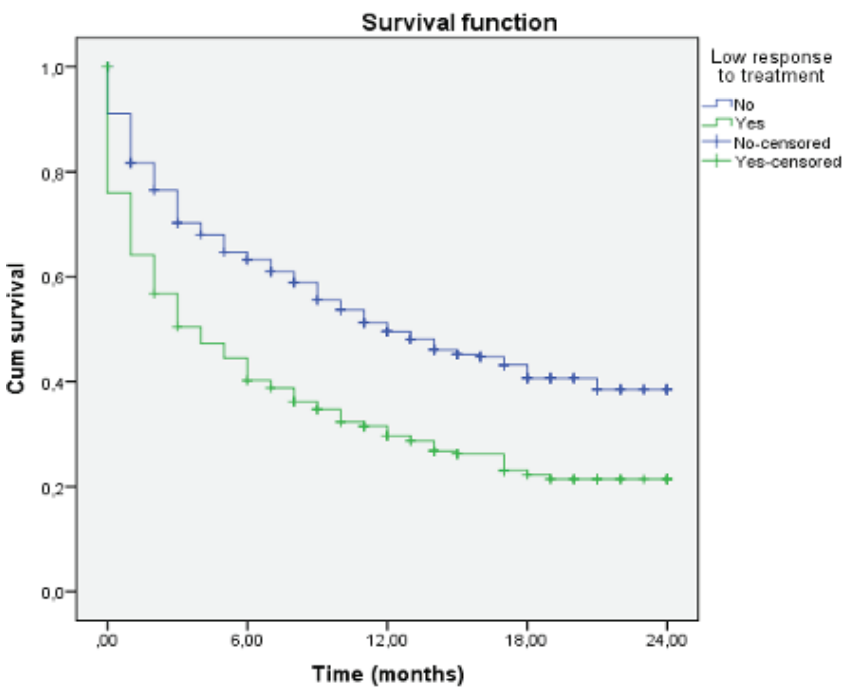

(d)

Figure 3. Kaplan-Meier global survival curves and significant predictors of mortality $(n=681)$. (a): NECPAL+ patients global survival. (b): Survival in NECPAL+ patients and significant functional decline, PPS $\leq 50$. (c): Survival in NECPAL+ in/outpatients. (d): Survival in NECPAL+ patients with low response to treatment. 


\section{Discussion}

The breakthrough of this multicentric study was the use of a direct prospective method aimed to improve cancer survival prediction and PC referral in hospital settings in Argentina. The overall survival was 8 months, which confirms that we identified patients in their last year of life or less. Furthermore, it enabled us to design a palliative care model (PCM) as part of a more extensive study and a prognosis model approach. This model has the potential to be replicated in other hospitals throughout Argentina [6].

The NECPAL tool was feasible and helpful in our multicentric setting to identify mortality risk factors coinciding with Spanish results [14, 18]. The 12 months' time frame is exactly the NECPAL tool's point of interest. After 12- and 24-month follow-up, the survival rate endorses the conceptual approach of typical trajectories of decline in ACD, including cancer [4, 10, 19, 20]. In Scotland, while PC is increasing, curative care is growing even faster in the last months of life. Therefore, identifying populations with limited prognoses is central to enhancing policymaking, service planning and delivery $[9,21]$.

NECPAL's predictive validity had already been tested in a Spanish cohort of a prevalence study, with high sensitivity and negative predictive value but limited specificity in predicting 24-month death [22]. Later, some NECPAL parameters have been independently associated with mortality risk in different populations [23]. In a previous study, we constructed a predictive model in one of the current Argentinian hospitals to identify individuals with PC needs for 24 months [8]. In that project, also focused on cancer patients, almost half of NECPAL+ patients had a significant functional decline. The concurrence of all such indicators correlated strongly with high mortality risk during the first month of follow-up. Half of the patients in that population died within 4 months suggests that the referral to PC services might have been too late. In the current study, the mean survival was two times the previous one. This outcome opened a new question about the potential influence of the systematic approach and the reflexive SQ on earlier referral to PC. The research team was involved with staff daily practice, both oncologists and PC teams. We considered this influence as positive, and it might be a catalytic agent looking for an earlier palliative approach.

Turrillas et al [9] pointed out that a prognostic tool using NECPAL variables selected based on clinicians' expertise and literary evidence can be accurate and helpful in predicting 2-year mortality in patients with advanced conditions [9]. Nutritional and functional decline, severe and refractory dyspnoea, multimorbidity, use of resources and specific disease indicators were potentially prognostic variables for mortality across four clinical groups and end-of-life trajectories: cancer, dementia and neurologic diseases, chronic organ failure and frailty [23].

A progressive increase in the mortality risk was observed based on the number of clinical factors in the NECPAL model ([9]. All six parameters were combined into three prognostic groups regardless of the indicator (0-2, 3-4 and 5-6 parameters). This model showed accuracy in predicting survival in oncological patients who were the illest. The prevalence of four out of six predictive variables was higher than in the other groups (non-cancer patients), including a high presence of the disease-specific criterion of severity, which could explain a better performance [9].

We have included cancer patients exclusively in the project. Frailty, which is strongly associated with survival rate, has been included as a specific criterion in the latest version of the NECPAL tool [9]. We did not assess frailty by using specific tools. However, this should be a future research field in our population.

There has been a significant increase in the use of PC services by oncologists. However, PC patients' referral occurs late in the trajectory of illness, at an average of 30-60 days before death. In addition, most families who refer to PC programmes state that they preferred an earlier consultation [24].

Hui et al [25] compared the quality of care between early (>3 months between first PC consultation and death) and late ( $\leq 3$ months) PC referral in cancer patients [25]. This cut-off was chosen because the median time from referral to death to the outpatient clinic was approximately 3 months. In addition, a PC referral is often triggered by symptom distress rather than prognosis [2]. However, the 'prognosis approach' should, from a pragmatic point of view, estimate prognosis together with PC needs, supporting oncologists in their daily practice at the clinical and organisational levels.

In the current study, the NECPAL tool identified these patients with PC needs and confirmed their mortality risk in 1 year. In addition, this systematic screening allowed us to assess patients' multidimensional needs by a multidisciplinary PC team in a mean of the last 8 months of their life (95\% Cl: 6.3-9.7) [26]. 
It is estimated that $69 \%-82 \%$ of cancer deaths would benefit from PC, improving quality of life, patient and caregiver distress and even survival [27]. As a result, multiple calls have been for integrating PC into standard oncology care to achieve the best outcomes [28-31]. Therefore, we admitted these patients to our PCM, collaborating with the oncologist and PC team, providing periodic assessment until death [26].

Despite the growing evidence supporting the effectiveness of palliative outpatient clinics, only 59\% of the National Cancer Institute-designated cancer centres reported having such clinics in the USA [24, 32]. Moreover, even with a PC clinic available, only 46\% of patients had their first PC visit in the outpatient setting at MD Anderson Cancer Center, Houston, Texas [2]. In contrast, we assessed 79\% of outpatients with advanced cancer and PC needs. It suggests that our PCM aimed to integrate PC into cancer follow-up. However, these findings should not be generalisable to other contexts because we probably did not reach the whole cancer outpatients sample.

\section{Limitations and strengths}

These results are directly applicable to the institutions involved, and it is not generalisable to other hospitals. One of the main strengths of this analysis is the involvement of three hospitals (two university hospitals, one of them oncological and a gastroenterological diseases referent hospital), allowing us to evaluate the PCM quality across medical conditions and care settings. Selection bias should be considered because identifying at-risk individuals with PC needs was based on clinical judgment. In addition, a substantial number of patients were classified as having functional or nutritional decline based on a subjective decision and not necessarily relying on validated criteria.

\section{Conclusions}

We propose that developing the 'palliative and prognosis approach' will respond to an urgent need to investigate the most effective but timeefficient method to assess patients' multidimensional needs with cancer and deliver timely PC. Despite the uncertainty in survival prediction, this model should facilitate clinical decision-making by providing an approximate timeframe (1 year or months). Future research should focus on validating new prognostic factors and linking them to decision-making. According to our earlier studies, the screening approach proved practical and accessible on a broader scale [6-8]. We want to make sure that everyone has access to the best cancer care possible. In addition to strengthening the timely palliative approach in national hospitals, the National Cancer Institute's National PC Programme could consider this methodology in future policymaking [15].

\section{Acknowledgments and funding}

The authors would like to acknowledge the valuable support from Institute Pallium Latinoamérica and its home-based care programme, as well as the PC and cancer teams from Lanari Institute, Roffo Institute and Udaondo Hospital. This research was funded by The National Cancer Institute (2016-2018 N¹006/2016; N³33/17).

\section{Author contributions}

All the authors have made substantial intellectual contributions to this article. For example, VT, VLL, MLD, PM, AS, GDS and XGB contributed to study design; VT, VLL, MLD, RT, EDM and SS in the data collection; VT, VLL, SDL and JMD in analysis and interpretation of data; VT, VLL and SDL in the writing of the manuscript and all authors in the decision to submit the manuscript for publication and revised the final version.

\section{Conflicts of interest}

The authors declare that they have no conflicts of interest. 


\section{List of abbreviations}

PC, Palliative care; ACD, Advanced chronic disease; PCM, Palliative care model; SQ, Surprise question; PPS, Palliative performance scale.

\section{References}

1. World Health Organization (2014) Strengthening of palliative care as a component of integrated treatment throughout the life course J Pain Palliat Care Pharmacother 28(2) 130-134 https://doi.org/10.3109/15360288.2014.911801 PMID: 24779434

2. Hui D, Hoge G and Bruera E (2021) Models of supportive care in oncology Curr Opin Oncol [Internet] 33 250-266 https://doi. org/10.1097/CCO.0000000000000733

3. Murray S and Amblàs J (2021) Palliative care is increasing, but curative care is growing even faster in the last months of life Br $\mathrm{J}$ Gen Pract 71(710) 410-411 https://doi.org/10.3399/bjgp21X716921 PMID: 34446408 PMCID: 8378580

4. Gómez-Batiste X, Martínez-Muñoz M and Blay C, et al (2014) Prevalence and characteristics of patients with advanced chronic conditions in need of palliative care in the general population: a cross-sectional study Palliat Med 28(4) 302-311 https://doi. org/10.1177/0269216313518266 PMID: 24403380

5. Gómez-Batiste X, Martínez-Muñoz M and Blay C, et al (2012) Identifying needs and improving palliative care of chronically ill patients: a community-oriented, population-based, public-health approach Curr Opin Support Palliat Care 6(3) 371-378 https://doi.org/10.1097/ SPC.0b013e328356aaed PMID: 22801465

6. Tripodoro VA, Llano V and De Lellis S, et al (2020) Modelo demostrativo de identificación precoz y atención continua de pacientes con cáncer y necesidades paliativas Rev Argent Salud Pública 126

7. Tripodoro VA, Rynkiewicz MC and Llanos V, et al (2016) Palliative care needs in advanced chronic illness Medicina 76(3) 139-147

8. Tripodoro VA, Llanos V and De Lellis S, et al (2019) Prognostic factors in cancer patients with palliative needs identified by the NECPAL CCOMS-ICOC tool Medicina 79(2) 95-103

9. Turrillas P, Peñafiel J and Tebé C, et al (2021) NECPAL prognostic tool: a palliative medicine retrospective cohort study BMJ Support Palliat Care [Internet] https://doi.org/10.1136/bmjspcare-2020-002567 PMID: 33593868

10. Boyd K and Murray SA (2010) Recognising and managing key transitions in end of life care BMJ 341 c4863 https://doi.org/10.1136/ bmj.c4863 PMID: 20847023

11. Charlson ME, Pompei P and Ales KL, et al (1987) A new method of classifying prognostic comorbidity in longitudinal studies: development and validation J Chronic Dis [Internet] 40 373-383 https://doi.org/10.1016/0021-9681(87)90171-8 PMID: 3558716

12. Bonilla P Cuidados paliativos en Latinoamérica Palliative care in Latin America Cuidados paliativos na América Latina [https://revistanutricionclinicametabolismo.org/index.php/nutricionclinicametabolismo/article/download/226/413?inline=1]

13. Estadísticas - Incidencia [Internet] Instituto Nacional del Cáncer [https://www.argentina.gob.ar/salud/instituto-nacional-del-cancer/ estadisticas/incidencia] Date accessed: 31/05/21

14. Calsina-Berna A, Martinez-Muñoz M and Bardés Robles I, et al (2018) Intrahospital mortality and survival of patients with advanced chronic illnesses in a tertiary hospital identified with the NECPAL CCOMS-ICO@ Tool J Palliat Med 21(5) 665-673 https://doi. org/10.1089/jpm.2017.0339 PMID: 29649401

15. Boletín Oficial de la República Argentina Resolución 1253 - E/2016 Programa Nacional de Cuidados Paliativos. Creación [Internet] (Boletín Oficial de la República Argentina) [https://www.boletinoficial.gob.ar/detalleAviso/primera/150263/20160902] Date accessed: $31 / 05 / 21$ 
16. Instrumento NECPAL CCOMS-ICO v3.0 [Internet] (Instituto Catalán de Oncología) [http://ico.gencat.cat/web/.content/minisite/ico/professionals/documents/qualy/arxius/NECPAL-3.0-ESPANOL_completo.pdf] Date accessed: 31/05/21

17. Lau F, Maida V and Downing M, et al (2009) Use of the Palliative Performance Scale (PPS) for end-of-life prognostication in a palliative medicine consultation service J Pain Symptom Manage 37(6) 965-972 https://doi.org/10.1016/j.jpainsymman.2008.08.003 PMID: 19232892

18. Amblàs-Novellas J, Murray SA and Espaulella J, et al (2016) Identifying patients with advanced chronic conditions for a progressive palliative care approach: a cross-sectional study of prognostic indicators related to end-of-life trajectories BMJ Open 6(9) e012340 https://doi.org/10.1136/bmjopen-2016-012340 PMID: 27645556 PMCID: 5030552

19. Gómez Batiste X, Blay C and Roca J, et al (2014) Manual de atención integral de personas con enfermedades crónicas avanzadas. Aspectos generales. Principios generales de la atención paliativa (Barcelona: Elsevier)

20. Maas EAT, Murray SA and Engels $\mathrm{Y}$, et al (2013) What tools are available to identify patients with palliative care needs in primary care: a systematic literature review and survey of European practice BMJ Support Palliat Care 3(4) 444-451 https://doi.org/10.1136/bmjspcare-2013-000527

21. Amblás J (2021) Catalan Model of Care for People with Frailty, Complex Chronic (CCP) and Advanced Chronic (ACP) Conditions 1st edn, ed J Amblás (Barcelona: Generalitat de Catalunya. Ministry of Health)

22. Gómez-Batiste X, Martínez-Muñoz M and Blay C, et al (2017) Utility of the NECPAL CCOMS-ICO $\odot$ tool and the surprise question as screening tools for early palliative care and to predict mortality in patients with advanced chronic conditions: a cohort study Palliat Med 31(8) 754-763 https://doi.org/10.1177/0269216316676647

23. Gómez-Batiste X, Turrillas $P$ and Tebé $C$, et al (2020) NECPAL tool prognostication in advanced chronic illness: a rapid review and expert consensus BMJ Support Palliat Care [Internet] https://doi.org/10.1136/bmjspcare-2019-002126

24. Bruera E, Hui $D(2010)$ Integrating supportive and palliative care in the trajectory of cancer: establishing goals and models of care $J$ Clin Oncol 28(25) 4013-4017 https://doi.org/10.1200/JCO.2010.29.5618 PMID: 20660825

25. Hui D, Kim SH and Roquemore J, et al (2014) Impact of timing and setting of palliative care referral on quality of end-of-life care in cancer patients Cancer 120(11) 1743-1749 https://doi.org/10.1002/cncr.28628 PMID: 24967463 PMCID: 4073257

26. Hui D (2015) Prognostication of survival in patients with advanced cancer: predicting the unpredictable? Cancer Control [Internet] 22 489-497 https://doi.org/10.1177/107327481502200415 PMID: 26678976 PMCID: 4769860

27. Pergolizzi D, Crespo I and Balaguer A, et al (2020) Proactive and systematic multidimensional needs assessment in patients with advanced cancer approaching palliative care: a study protocol BMJ Open 10(2) e034413 https://doi.org/10.1136/bmjopen-2019-034413 PMID: 32024792 PMCID: 7045209

28. Bakitas MA, Tosteson TD and Li Z, et al (2015) Early versus delayed initiation of concurrent palliative oncology care: patient outcomes in the ENABLE III randomized controlled trial J Clin Oncol 33(13) 1438-1445 https://doi.org/10.1200/JCO.2014.58.6362 PMID: 25800768 PMCID: 4404422

29. Dahlin CM, Kelley JM and Jackson VA, et al (2010) Early palliative care for lung cancer: improving quality of life and increasing survival Int J Palliat Nurs 16(9) 420-423 https://doi.org/10.12968/ijpn.2010.16.9.78633 PMID: 20871495

30. Kaasa S, Loge JH and Aapro M, et al (2018) Integration of oncology and palliative care: a Lancet Oncology Commission Lancet Oncol 19(11) e588-e653 https://doi.org/10.1016/S1470-2045(18)30415-7 PMID: 30344075

31. Bauman JR and Temel JS (2014) The integration of early palliative care with oncology care: the time has come for a new tradition J Natl Compr Canc Netw 12(12) 1763-1771 [quiz 1771] https://doi.org/10.6004/jnccn.2014.0177 PMID: 25505216 PMCID: 5728091

32. Hui D, Elsayem A and De la Cruz M, et al (2010) Availability and integration of palliative care at US cancer centers JAMA 303(11) 1054-1061 https://doi.org/10.1001/jama.2010.258 PMID: 20233823 PMCID: 3426918 